\title{
A new robust oxygen-temperature sensor for aquatic eddy covariance measurements
}

\author{
Peter Berg, ${ }^{* 1}$ Dirk J. Koopmans, ${ }^{1,2}$ Markus Huettel, ${ }^{3}$ Hua Li, ${ }^{4}$ Kosuke Mori, ${ }^{4}$ Alfred Wüest ${ }^{5,6}$ \\ ${ }^{1}$ Department of Environmental Sciences, University of Virginia, Charlottesville, Virginia \\ ${ }^{2}$ School of Freshwater Sciences, University of Wisconsin-Milwaukee, Milwaukee, Wisconsin \\ ${ }^{3}$ Department of Earth, Ocean and Atmospheric Science, Florida State University, Tallahassee, Florida \\ ${ }^{4}$ JFE Advantech, Nishinomiya, Japan \\ ${ }^{5}$ Physics of Aquatic Systems Laboratory, Margaretha Kamprad Chair, EPFL-ENAC-IEE-APHYS, Lausanne, Switzerland \\ ${ }^{6}$ Surface Waters - Research and Management, Eawag, Swiss Federal Institute of Aquatic Science and Technology, \\ Kastanienbaum, Switzerland
}

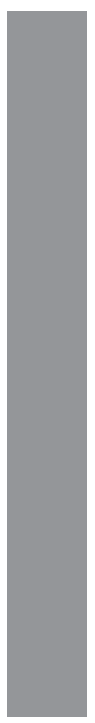

\begin{abstract}
The fragility of thin Clark-type glass microelectrodes used in aquatic eddy covariance measurements of benthic oxygen fluxes is a challenge when using this powerful technique. This study presents a new fastresponding dual oxygen-temperature sensor for eddy covariance measurements that is far more robust. Response time tests in the lab, where the sensor was inserted from air into water, revealed $90 \%$ response times of $0.51 \mathrm{~s}$ and $0.34 \mathrm{~s}$ for oxygen and temperature measurements, respectively. In wave tank tests, the new sensor showed no stirring sensitivity in contrast to Clark-type microelectrodes. Other tests in a flume and in a particle-free water tank revealed how close the sensor can be positioned to the measuring volume of the Acoustic Doppler Velocimeter without disturbing velocity recordings. In field tests at river sites, all $>24 \mathrm{~h}$, the new sensor recorded high-quality eddy covariance data for the entire deployment. Similar positive results were obtained in deployments at a marine site with unidirectional current flow overlaid with minor wave action. Concurrently deployed eddy covariance systems based on the new sensor and a traditional Clark-type microelectrode revealed that they recorded statistically equivalent fluxes and similar velocity-oxygen cospectra until the microelectrode broke after $2 \mathrm{~h}$. The significant increase in robustness of the new sensor was achieved by relying on a larger sensor tip. This put some constrains on how the sensor should be deployed and fluxes extracted, but given the substantial gain in performance, it is a viable alternative for eddy covariance measurements in many aquatic environments.
\end{abstract}

Oxygen fluxes over the sediment-water interface are widely used as a proxy for benthic carbon mineralization and production rates in marine and freshwater environments (Canfield et al. 1993; Glud 2008). Therefore, these fluxes play an important role when evaluating the health of aquatic ecosystems and in local and global carbon budget estimates. Yet, the magnitudes of oxygen fluxes and their variability in space and time are not well-documented for many benthic environments, which diminishes the utility of such oxygen-flux based calculations.

The lack of dependable benthic oxygen flux data is first and foremost caused by the limitations of traditional flux methods. For example, in situ chambers, which enclose a small area of the benthic surface, alter the flow and light field for the incubated water and sediment, which can affect the flux measurements made to characterize environments

*Correspondence: pb8n@virginia.edu with permeable sands and macrophytes such as seagrass beds (Cook et al. 2007; Hume et al. 2011; Berg et al. 2013). Also, chambers cut off natural exchange of constituents with the water column, which may influence biological and biogeochemical processes, consequently affecting the measured fluxes. Similarly, the open-water flux method (Odum 1956; Hall et al. 2007; Holtgrieve et al. 2010), which derives fluxes from an oxygen mass-balance for the entire water column, is limited by inaccuracies often associated with the air-water exchange of oxygen (Wanninkhof et al. 1990; Raymond and Cole 2001; Raymond et al. 2012). This exchange is estimated with an exchange coefficient that is rarely measured, extrapolated from general empirical models (Raymond et al. 2012), or fitted statistically (Holtgrieve et al. 2010), and thereby uncertainties are introduced. Also, because benthic fluxes and their dynamics are extracted from concentrations representing the entire water column, the temporal resolution of this method is limited. 


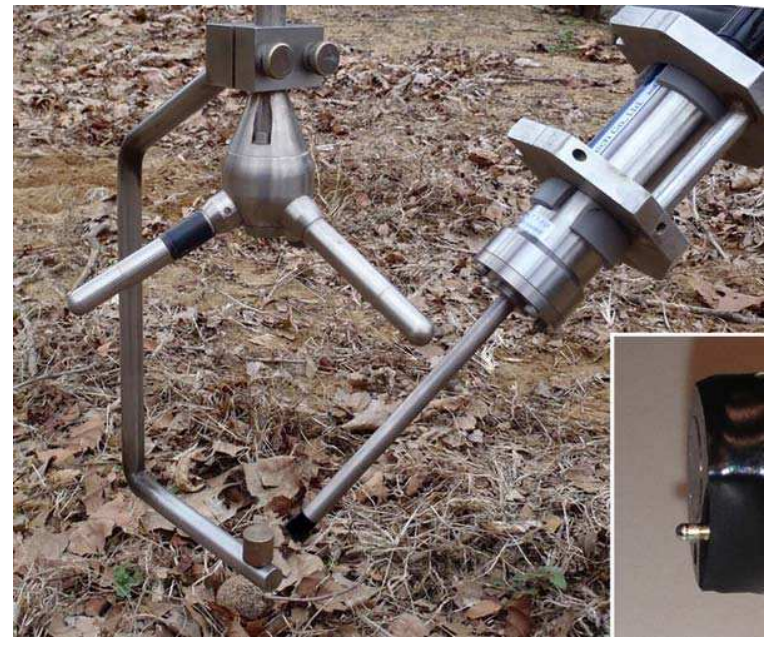

Fig. 1. Alignment of the oxygen-temperature sensor adjacent to the measuring volume of the Acoustic Doppler Velocimeter (ADV) before field deployment. The location of the measuring volume is marked by the brass cylinder on the alignment tool (at left, steel bracket) which is removed before deployment. The sensor is oriented $45^{\circ}$ off the vertical axis of the ADV. The insert shows a close-up side view of the sensor tip with its circular oxygen-sensitive foil and thermistor. The cylindrical stem of the sensor has a diameter of $10 \mathrm{~mm}$.

The aquatic eddy covariance technique (Berg et al. 2003) overcomes these limitations and has, despite initial technical challenges and substantial start-up and running costs, proven to be a powerful approach for oxygen flux measurements in many environments. To date, these include marine and freshwater muddy sediments (Berg et al. 2003; Brand et al. 2008; McGinnis et al. 2008), permeable sands (Kuwae et al. 2006; Berg and Huettel 2008; Reimers et al. 2012), deep ocean sediments (Berg et al. 2009), rock surfaces (Glud et al. 2010), oyster beds (Reidenbach et al. 2013), coral reefs (Long et al. 2013; Cathalot et al. 2015; Rovelli et al. 2015), seagrass meadows (Hume et al. 2011; Rheuban et al. 2014; Long et al. 2015a), vertical cliffs (Glud et al. 2010), and down-facing sea-ice surfaces (Long et al. 2012). The noninvasive nature of the eddy covariance technique allows studies of relationships between benthic oxygen fluxes and their controls that cannot be revealed by other flux methods. These relationships include the link between oxygen flux and varying current flow over permeable sandy sediments (Berg and Huettel 2008; Berg et al. 2013; McGinnis et al. 2014), cohesive siltysand substrates (Glud et al. 2010), and coral reefs (Long et al. 2013; Rovelli et al. 2015). Other eddy covariance studies have identified patterns in oxygen flux that are not yet fully understood. These include hysteresis effects in daytime oxygen release from dense seagrass meadows with a release that is several times larger in the morning than in the afternoon despite similar light levels (Rheuban et al. 2014).

All eddy covariance studies mentioned above have relied on thin Clark-type glass microelectrodes for the oxygen con- centration measurements, and these sensors represent a challenge when using this technique. The microelectrodes are typically constructed with outer tip diameters of 20-100 $\mu \mathrm{m}$ and membrane-filled openings of only 1-5 $\mu \mathrm{m}$ to achieve the required rapid response. As a result, they are difficult to handle prior to deployment and are highly fragile; they break by impact with even small pieces of suspended natural debris or larger sediment grains, or by contact with fish seeking shelter under the eddy covariance system. It is not uncommon for useful oxygen data to be recorded only during $10-20 \%$ of typical $24 \mathrm{~h}$ long deployments due to electrode breakage or malfunctioning (Berg et al. 2013). This adds significant time and cost to field trips and cruises that set out to obtain a certain amount of high-quality data. It also prohibits long-term flux measurements in most natural waters.

In atmospheric sciences, the eddy covariance method became the standard flux measuring technique after initial sensor problems were solved (Baldocchi 2003; Aubinet et al. 2012; Burba 2013). Similarly, improving the oxygen sensor is an important step to further advance the eddy covariance technique to a widely used standard approach for aquatic flux measurements. The goal of this study was to develop a new highly robust oxygen sensor with a fast response that can significantly improve the reliability of such measurements.

\section{Materials and procedures}

\section{New sensor}

The new dual oxygen-temperature sensor was developed in collaboration with JFE Advantech (Japan). The factorycalibrated sensor uses a small planar optode, and oxygen concentrations are derived from fluorescence life-time measurements (Klimant et al. 1995; Holst et al. 1997; Holst et al. 1998). This makes it less sensitive to environmental factors such as fouling and signal amplitude loss compared to sensors based on fluorescence intensity measurements. The temperature is recorded along with the optical oxygen signal, which allows the oxygen concentration output from the new sensor to be temperature-corrected. Furthermore, because oxygen is not consumed at the photo-active sensor surface, one of the underlying physical mechanisms that makes most electrochemical oxygen sensors sensitive to surrounding velocities (stirring sensitivity) has effectively been removed. The excitation light source and light detector are mounted inside the end of a $160 \mathrm{~mm}$ long and $10 \mathrm{~mm}$ outside diameter stainless steel tube (Fig. 1). The oxygen-sensitive foil with a diameter of $5.6 \mathrm{~mm}$ is factory-mounted in a replaceable circular plastic disc that also provides a watertight cover over the excitation light source and light detector (Fig. 1, insert). Two small titanium pins at the end of the steel tube fit into two holes in the plastic disc to ensure correct and consistent positioning when discs are replaced, an operation that can easily be performed by a user. $\mathrm{A}<1 \mathrm{~mm}$ diameter thermistor for 
temperature measurements is located next to the oxygensensitive foil (Fig. 1, insert). The $160 \mathrm{~mm}$ tube is connected to a wider stainless steel cylinder $(54 \mathrm{~mm}$ diameter, Fig. 1) that holds the sensor electronics. The sensor requires a power input of $12 \mathrm{~V} \mathrm{DC}$ and provides output as two analog signals $(0-5 \mathrm{~V})$, one for oxygen and one for temperature. These specifications allow "plug-and-play" connection to the Nortek Vector Acoustic Doppler Velocimeter (ADV) that we use for eddy covariance velocity measurements. As a result, the ADV can, via one single custom-made cable, both power the sensor and simultaneously record its dual output data at frequencies up to $64 \mathrm{~Hz}$.

The sensor was thoroughly evaluated in both lab and field tests using our "standard" eddy covariance system (Berg and Huettel 2008; Berg et al. 2013) except that the usual Clarktype microelectrode and its amplifier were replaced by the new sensor.

\section{Lab tests}

Lab tests were performed to determine the dual sensor's response times for both oxygen and temperature measurements, how it potentially disturbs the velocity measurements depending on its position relative to the ADV's measuring volume, and its stirring sensitivity.

The $90 \%$ sensor response time $\left(t_{90 \%}\right)$ was measured by inserting the sensor tip from air into water baths, in which either the oxygen concentration or temperature differed from that of the ambient air. The dual sensor output data were recorded at $64 \mathrm{~Hz}$ and used to determine $t_{90 \%}$ with a $\sim$ $1 / 64 \mathrm{~s}$ resolution. During field deployments, the sensor is submerged and positioned at some distance from the center of the ADV's measuring volume. This physical distance, combined with the time it takes the oxygen concentration of the water touching the oxygen sensitive foil to equilibrate with the concentration outside the boundary layer that forms over the foil, results in a time lag between the oxygen data and the velocity data, which is larger than $t_{90 \%}$. This time lag and how it affects the calculated fluxes is evaluated below (see Assessments and Discussion).

The downstream distance between the new sensor and the ADV's measuring volume, where the sensor affects the velocity recordings, was determined in a $30 \mathrm{~cm} \times 30 \mathrm{~cm} \times$ $4.0 \mathrm{~m}$ flume with constant unidirectional flow, shear generated turbulence, and seeded with 8-13 $\mu \mathrm{m}$ particles (Nortek, Norway). With the sensor positioned at a $45^{\circ}$ angle as illustrated in Fig. 1, effects on the velocity measurements were assessed at distances of $2.0 \mathrm{~cm}, 1.5 \mathrm{~cm}, 1.0 \mathrm{~cm}, 0.75 \mathrm{~cm}$, $0.50 \mathrm{~cm}, 0.25 \mathrm{~cm}$, and $0 \mathrm{~cm}$, measured from the edge of the ADV's measuring volume to the edge of the sensor tip. For each distance, velocity data were recorded at $64 \mathrm{~Hz}$ for multiple 5 min long periods, each producing one horizontal mean velocity and three standard deviations, one for each of the ADV's velocity components. These data were compared to determine the distance at which the sensor influenced the velocity measurements.

The same question was also addressed in a different way. In other lab tests, performed in particle-free stagnant water, the new sensor was positioned as before at different distances from the ADV's measuring volume to determine at what point the ADV could detect an acoustic backscatter from the sensor tip. At each distance, here equaling $10 \mathrm{~cm}, 5.0 \mathrm{~cm}$, $4.0 \mathrm{~cm}, 3.0 \mathrm{~cm}, 2.5 \mathrm{~cm}, 2.0 \mathrm{~cm}, 1.5 \mathrm{~cm}, 1.0 \mathrm{~cm}, 0.75 \mathrm{~cm}$, $0.50 \mathrm{~cm}, 0.25 \mathrm{~cm}$, and $0 \mathrm{~cm}$, data were recorded at $64 \mathrm{~Hz}$ for 2 min to give three average amplitudes, one for each ADV beam. These amplitudes are standard ADV outputs which, under normal field use without any other instruments near the ADV, represent the backscatter strength from particles moving through the measuring volume. Amplitudes must exceed a certain level to ensure high-quality velocity data.

To determine the new sensor's sensitivity to varying velocity around its tip (stirring sensitivity), the oxygen sensor and ADV were submerged in a wave tank and exposed to uniform wave motions for $5 \mathrm{~min}$, while concentration and velocity data were recorded at $64 \mathrm{~Hz}$. As a reference, a similar dataset was recorded with a Clark-type microelectrode using the same experimental settings. In each case, the $64 \mathrm{~Hz}$ data were reduced to $16 \mathrm{~Hz}$ by averaging every four data points to reduce noise before being examined for stirring sensitivity.

\section{Field tests}

The new sensor was tested during five deployments, three in the Hardware River (Virginia), and two at a marine site located near Long Key (Florida Keys).

The stretch of the Hardware River, where the tests were conducted, had a fairly linear run with a width of $\sim 8 \mathrm{~m}$, a water depth which varied between $0.5 \mathrm{~m}$ and $1 \mathrm{~m}$, and a base discharge flow of $\sim 1 \mathrm{~m}^{3} \mathrm{~s}^{-1}$ (Fig. 2a). Typical surface flow velocities were $\sim 15 \mathrm{~cm} \mathrm{~s}^{-1}$. The river bottom was a mixture of sand, gravel, and small stones with some microalgal biofilms on benthic surfaces.

The three test deployments in the Hardware River were initiated on 01 April, 21 June, and 22 June 2013, all with deployment times $>24 \mathrm{~h}$ to cover full diurnal cycles. In each case, the eddy covariance instrument was positioned by wading. Care was taken to avoid disrupting the upstream bottom area from which the flux signal originated, the so-called footprint (Berg et al. 2007). Care was also taken to ensure that the instrument was as level as possible to minimize post processing rotations of the velocity field to correct for instrument tilt (Lee et al. 2004; Lorrai et al. 2010; Lorke et al. 2013). The measuring height above the river bed varied from $14 \mathrm{~cm}$ to $16 \mathrm{~cm}$ as confirmed by the ADV's bottom echo recorded at the start of each deployment. Finally, the edge of the new oxygen sensor was positioned $1.5 \mathrm{~cm}$ downstream of the edge of the ADV's measuring volume so that water passed through this volume before sweeping over the angled oxygen sensitive foil and thermistor tip (Fig. 2a). This setup ensured minimal, 


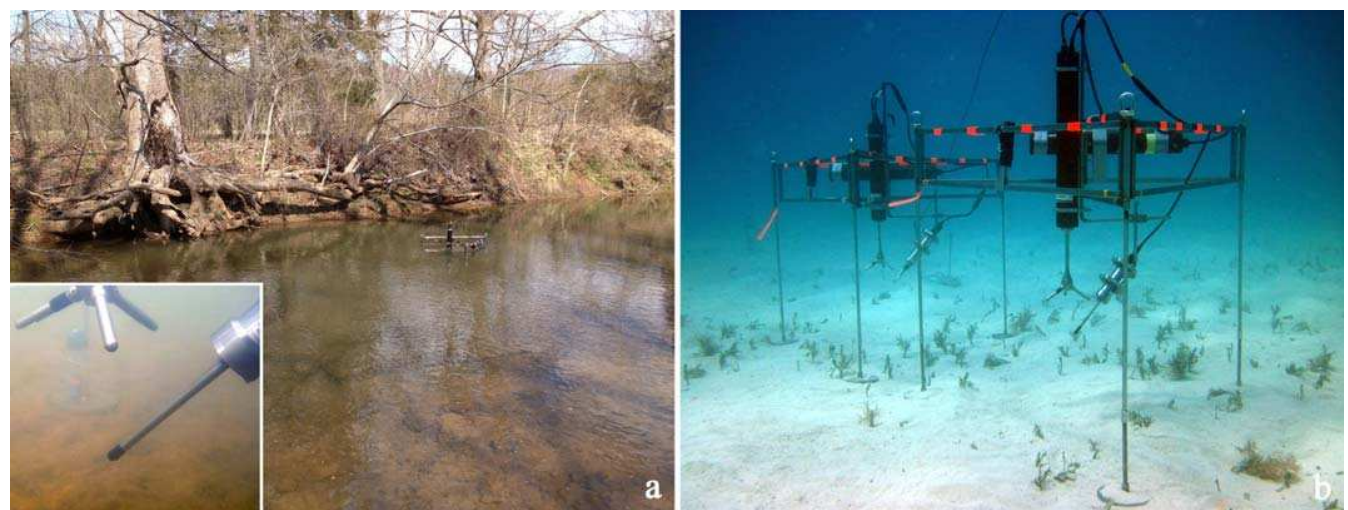

Fig. 2. (a) Test deployment in the Hardware River (01 April 2013, data shown below). The inset shows a close-up view of the new oxygentemperature sensor and ADV's sensor head above. The measuring volume was located $14 \mathrm{~cm}$ above the river bed. Flow was from left to right. In the background, one of the instrument frame legs with a PAR sensor attached is seen. (b) Side-by-side deployment in the Florida Keys (16 August 2013 , data shown below) of a system with the new sensor (foreground) and a traditional system with a Clark-type microelectrode. A fairly large measuring height of $28 \mathrm{~cm}$ above the bed was used due to the periodic presence of 10-15 cm high ripples.

if any, disturbance of the current flow. Data were recorded at $64 \mathrm{~Hz}$ continuously throughout the deployments. Supporting environmental variables measured in each deployment allowed interpretation of eddy fluxes and verification of data recorded with the new sensor. These variables included photosynthetically active radiation (PAR) and mean oxygen concentration. Values of PAR at the measuring height were recorded every 5 min using two independent submersible PAR sensors (Odyssey, Dataflow Systems, New Zealand). Mean oxygen concentration at the measuring height was recorded every 15 min with a submersible independent oxygen optode (miniDOT, PME, U.S.A.).

The Florida Keys site (Fig. 2b) was located $10 \mathrm{~km}$ southeast of Long Key and had a water depth of $9 \mathrm{~m}$. The tidal height range was $60 \mathrm{~cm}$, and current velocities in the range of $2-14 \mathrm{~cm} \mathrm{~s}^{-1}$ were often unidirectional for many hours at a time, but were periodically overlaid with wave motions. Due to the latter, distinct $10-15 \mathrm{~cm}$ high ripples often formed on the seabed which consisted of carbonate sand (Fig. 2b).

That two test deployments were initiated on 12 August 2013 and 16 August 2013, using the instrument setup as described above for the Hardware River with two exceptions: A larger measuring height of $28 \mathrm{~cm}$ above the bed was used due to the periodic presence of sand ripples, and a larger distance of $2.0-2.5 \mathrm{~cm}$ was used between the edge of the ADV's measuring volume and the edge of the new sensor to compensate for reduced backscatter from suspended particles in the clear water. During the 16 August deployment, a traditional eddy covariance system with a Clark-type microelectrode was positioned next to the test system (Fig. 2b). The traditional system was programmed to record data in burst mode resulting in successive 15 min time intervals with 14.5 min of $64 \mathrm{~Hz}$ data and a 0.5 min pause. For more details on this system and its preparation and setup, see Hume et al.
(2011) and Berg et al. (2013). The microelectrode tip was positioned a few mm away from the edge of the ADV's measuring volume.

\section{Eddy flux extractions}

Fluxes of oxygen and heat were extracted from the raw eddy covariance data following the same multi-step process. The process is briefly described below for oxygen fluxes. First, if the disc with the oxygen sensitive foil mounted on the new sensor was replaced, the sensor was recalibrated against measured concentration changes recorded concurrently with the independent oxygen optodes. Because all discs contained the same type of oxygen sensitive foil, this recalibration only lead to minor adjustments of the measured concentrations. In the case of the two-system deployment in the Florida Keys (Fig. 2b), the oxygen concentrations from the Clark-type microelectrode were further calibrated against the new sensor to give the best possible comparison of fluxes from the two systems. All $64 \mathrm{~Hz}$ data were then reduced to $8 \mathrm{~Hz}$ data (Berg et al. 2009), which reduces noise while providing sufficient resolution to describe the entire frequency spectrum carrying a detectable flux signal. This assumption was validated by comparing the resulting fluxes to those calculated from selected segments of $64 \mathrm{~Hz}$ data.

Oxygen fluxes, one for each $15 \mathrm{~min}$ data segment (14.5 min for the traditional system with a Clark-type microelectrode), were extracted from the $8 \mathrm{~Hz}$ data using the software package EddyFlux version 2.01 (P. Berg unpubl.). This software first rotates the flow velocity field for each specified data segment to correct for any sensor tilt (Lee et al. 2004; Lorrai et al. 2010; Lorke et al. 2013). This two-axis rotation brings the transverse and vertical mean velocities to zero for each data segment. The turbulent fluctuating component of the vertical velocity and associated oxygen concentration were then calculated for each 15 min segment by linear 

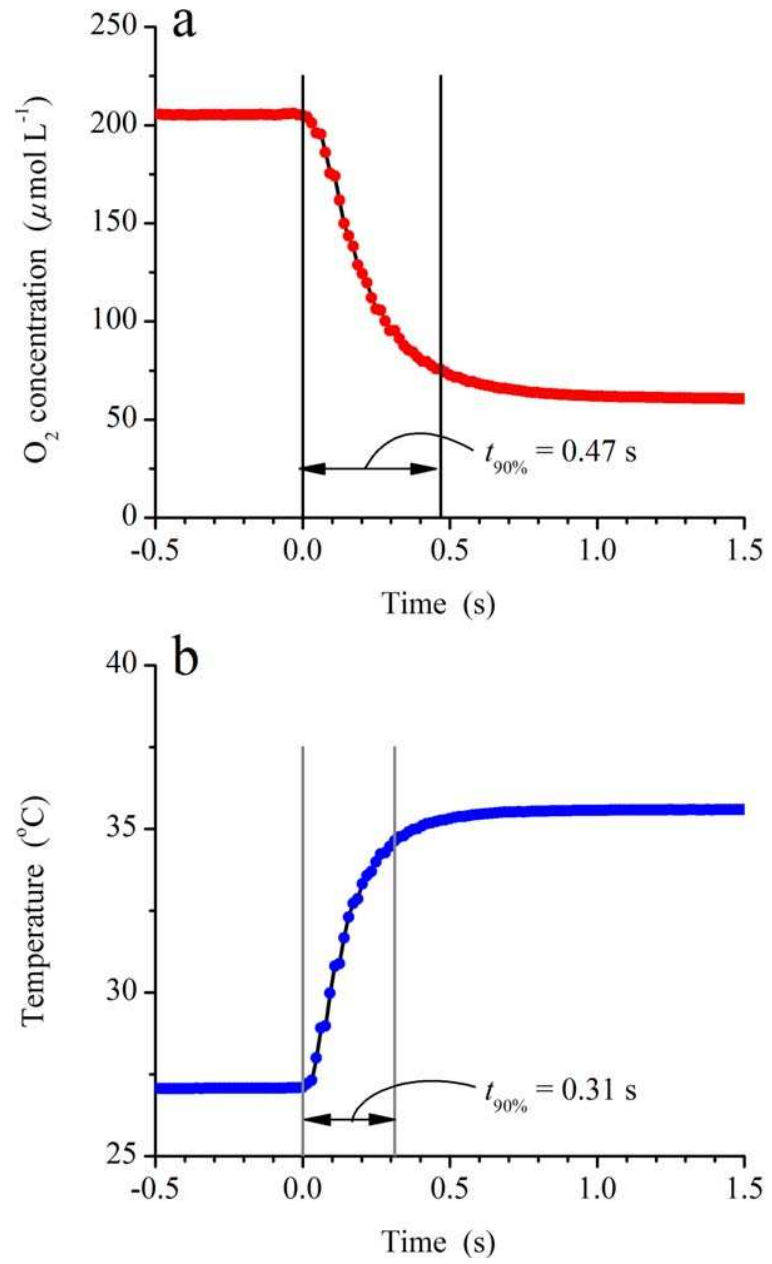

Fig. 3. Response time experiments with the new oxygen-temperature sensor. The sensor was moved rapidly from air into water baths with either low oxygen water (a) or warm water (b).

detrending (Lee et al. 2004; Berg et al. 2009). As the last step, mean fluxes and cumulative fluxes for each $15 \mathrm{~min}$ interval were calculated from these two fluctuation components. A more detailed description of this flux extraction protocol, including our standard data quality check used for Clark-type microelectrode measurements, is given by Lorrai et al. (2010), Hume et al. (2011), and Berg et al. (2013).

For the system with a Clark-type microelectrode, a time shift correction of the oxygen data relative to the velocity data (Fan et al. 1990; McGinnis et al. 2008; Lorrai et al. 2010) was deemed unnecessary in the absence of a local extremum near $1 \mathrm{~Hz}$ in the cumulative cospectra of the oxygen concentration and the vertical velocity (Berg et al. (2013), see also cospectra below). However, due to the new sensor's longer response time relative to a typical Clark-type microelectrode $(0.5 \mathrm{~s}$ vs. $\sim 0.3 \mathrm{~s}$, see below), combined with its position farther downstream from the ADV's measuring volume $(1.5-2.5 \mathrm{~cm})$, a time shift correction was applied to all data recorded with the new sensor. This was done by repeating the flux extraction procedure outlined above, while shifting the $8 \mathrm{~Hz}$ oxygen concentration data back in time by $1 / 8 \mathrm{~s}$ at a time until the numerically largest flux was found. This was first done for each 15 min data segment separately. Then, the average time shift was calculated for a number of consecutive data segments with significant oxygen fluxes, and imposed on all data in the deployment.

For several consecutive data segments in each deployment, cumulative cospectra of the oxygen concentration and the vertical velocity were calculated using the software package Spectra version 1.2 (P. Berg unpubl.) to determine the eddy frequencies that carried the flux signal. Because high-frequency flux contributions were the focus of these spectral analyses, running mean detrending with a fairly narrow filter window (60 s) was used.

\section{Assessments}

\section{Lab tests}

An example of $90 \%$ response times $\left(t_{90 \%}\right)$ determined by moving the oxygen-temperature sensor rapidly from air into water baths with either low oxygen water or warm water is shown in Fig. 3. Averaged over all trials, $t_{90 \%}$ equaled $0.51 \pm 0.01 \mathrm{~s}(\mathrm{SE}, n=7)$ for oxygen and $0.34 \pm 0.01 \mathrm{~s}$ (SE, $n=9$ ) for temperature. The $t_{90 \%}$ value for oxygen is slightly larger than or comparable to those reported for the traditional Clark-type microelectrodes $\left(t_{90 \%} \leq 0.3-0.5 \mathrm{~s}\right)$ used in recent eddy covariance work (Attard et al. 2014, 2015; Rovelli et al. 2015) and in the middle of the range of those for thin optical fiber sensors $\left(t_{90 \%} \leq 0.3-0.8 \mathrm{~s}\right)$ used in other new studies (Kreling et al. 2014; Long et al. 2015b; Murniati et al. 2015). The $t_{90 \%}$ value for temperature is larger than the one $\left(t_{90 \%}=0.10 \mathrm{~s}\right)$ determined by Crusius et al. (2008) for a sensor used to measure benthic heat fluxes.

The transport of oxygen through the boundary layer that forms over the sensor's oxygen sensitive foil during field deployments will increase the sensor response time relative to the $t_{90 \%}$ value reported above. However, the concentration equilibration between the free flowing water and the water at the smooth foil surface should not be confused with molecular diffusion across a thin layer of stagnant water as, for example, is found over muddy aquatic sediments (Lin et al. 1953; Jørgensen and Revsbech 1985; Gundersen and Jørgensen 1990). The boundary layer, over the foil and the plastic disc in which the foil is mounted (Fig. 1, insert), is in classic fluid dynamics referred to as a boundary layer flow along a flat smooth surface with a sharp leading edge (Schlichting 1979). The mathematical description of this flow states that the velocity inside the boundary layer, although reduced, only equals zero at the disc and foil surface itself. Thus, the advective transport inside the boundary layer over the short distance from the disc's edge to the foil $(\sim 1 \mathrm{~mm})$ will significantly speed up this equilibration process. In addition, the short distance, combined with the 


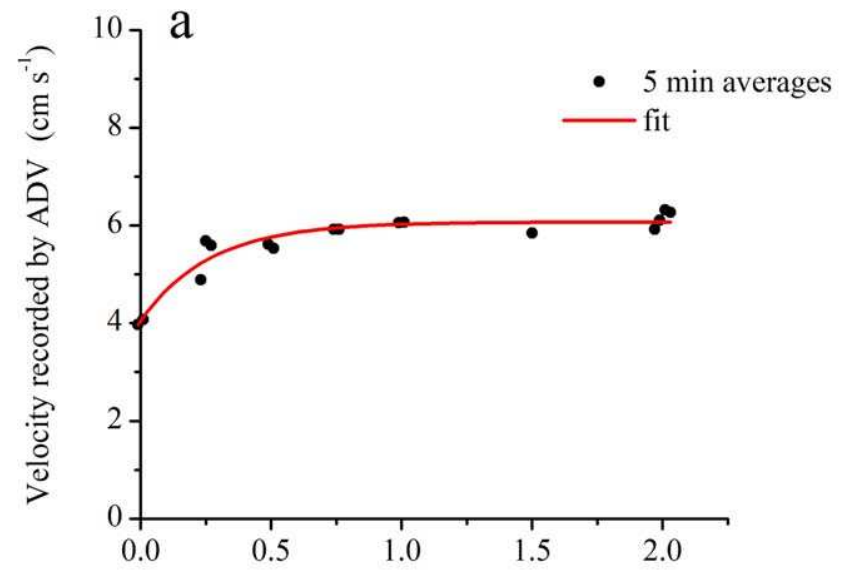

Distance between sensor and measuring volume of the ADV $(\mathrm{cm})$

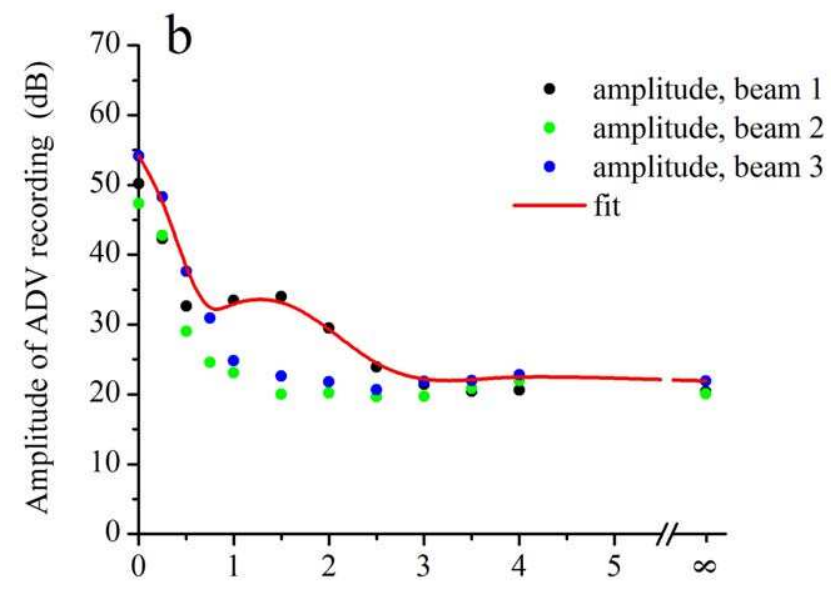

Distance between sensor and measuring volume of the ADV $(\mathrm{cm})$

Fig. 4. Lab tests designed to examine how close the new sensor can be positioned to the ADV's measuring volume. The distance was measured from the edge of the ADV's measuring volume to the edge of the sensor tip, and with the new sensor positioned at a $45^{\circ}$ angle as illustrated in Fig. 1. (a) Tests performed in a flume with particle-seeded water at a mean flow velocity of $\sim 6 \mathrm{~cm} \mathrm{~s}^{-1}$. (b) Tests performed in a tank with particle-free stagnant water. See text for details.

compression of the boundary layer due to the oxygen sensor's $45^{\circ}$ angle relative to the main current direction (Fig. 1), ensures an ultra-thin boundary layer with a rapid transport across it. As a result, only a small increase in response time is expected for oxygen due to this equilibration process through the boundary layer.

Due to the small size of the thermistor tip $(<1 \mathrm{~mm}$ diameter, Fig. 1), the determined $t_{90 \%}$ value for temperature is likely a good representative value for how the sensor will perform during field deployments.

Because of the sensor's tip size, it must be positioned at some distance from the ADV's measuring volume in order not to affect the velocity measurements. The result of the two different lab tests in which this was examined is shown in Fig. 4. The distance referred to in both cases was measured from the edge of the ADV's measuring volume to the edge of the sensor tip, and with the new sensor positioned at a $45^{\circ}$ angle (Fig. 1).

A significant drop in measured mean velocity was found when the sensor tip was positioned closer than $0.5 \mathrm{~cm}$ to the ADV's measuring volume (Fig. $4 \mathrm{a}$, one-way ANOVA, $p=0.05$ ). A fit to the data revealed a $5 \%$ drop in mean velocity at $0.5 \mathrm{~cm}$ distance. As a representative for key turbulent properties, the standard deviations of the three velocity components were examined the same way. For all distances, including those where changes were seen in the mean current velocity (Fig. 4a), the three standard deviations were statistically the same.

Potential flow theory (Schlichting 1979) for flows around solid objects, here the tip of the new sensor, suggests that upstream mean flow diversions are independent of mean current flow velocity. We therefore assess that our flume results obtained at $\sim 6 \mathrm{~cm} \mathrm{~s}^{-1}$ apply to other current velocities too.

The test performed in stagnant particle-free water (Fig. 4b) revealed a somewhat more stringent requirement for the distance between the two sensors. While no effect of the new sensor was seen for distances larger than $3.0 \mathrm{~cm}$, its backscatter increased noticeably in the interval from $3.0 \mathrm{~cm}$ to $1.5 \mathrm{~cm}$, then reached a plateau in the $1.5-0.75 \mathrm{~cm}$ interval before increasing sharply again. Based on the backscatter from natural particles found in our previous eddy covariance field work and the requirement that this backscatter should be at least $15 \mathrm{~dB}$ greater than that from the new sensor itself (A. Lohrmann pers. comm., Nortek, Norway), we assessed that a distance between the ADV's measuring volume and the new sensor in the $0.5-2.5 \mathrm{~cm}$ range is adequate for most field conditions. For example, the amplitude found by Berg et al. (2013) in the clear spring-fed Wakulla River was $47 \mathrm{~dB}$, which according to Fig. $4 \mathrm{~b}$ translates to a minimum distance of $1.7 \mathrm{~cm}$. For the more murky marine site described by Berg and Huettel (2008) with an amplitude of $58 \mathrm{~dB}$, the results in Fig. $4 \mathrm{~b}$ give a minimum distance of $0.4 \mathrm{~cm}$.

Some of the results presented above were used to evaluate how much of the total flux may potentially be lost by an eddy covariance system based on the new sensor. For this purpose, we assumed field conditions, in which a large fraction of the flux signal was carried by high-frequency turbulent eddies (e.g., energetic shallow water environments) as those are more challenging to capture by any eddy covariance system. The results of the following calculation, explained in steps below, should be considered conservative.

A sinusoidal fluctuation in vertical velocity with a frequency of $0.5 \mathrm{~Hz}$ was assumed at the location of the ADV's measuring volume (Fig. 5a). At the same location, a perfect in phase fluctuation was also assumed for the oxygen concentration (Fig. 5b, black line). The new sensor was assumed to be positioned downstream from the ADV's measuring volume so that the oxygen fluctuations reached the center of the foil with a $3 / 7$ s delay (Fig. 5b, red line). This delay is, for example, consistent with a distance of $3 \mathrm{~cm}$ between the center of the ADV's measuring volume and that of the 

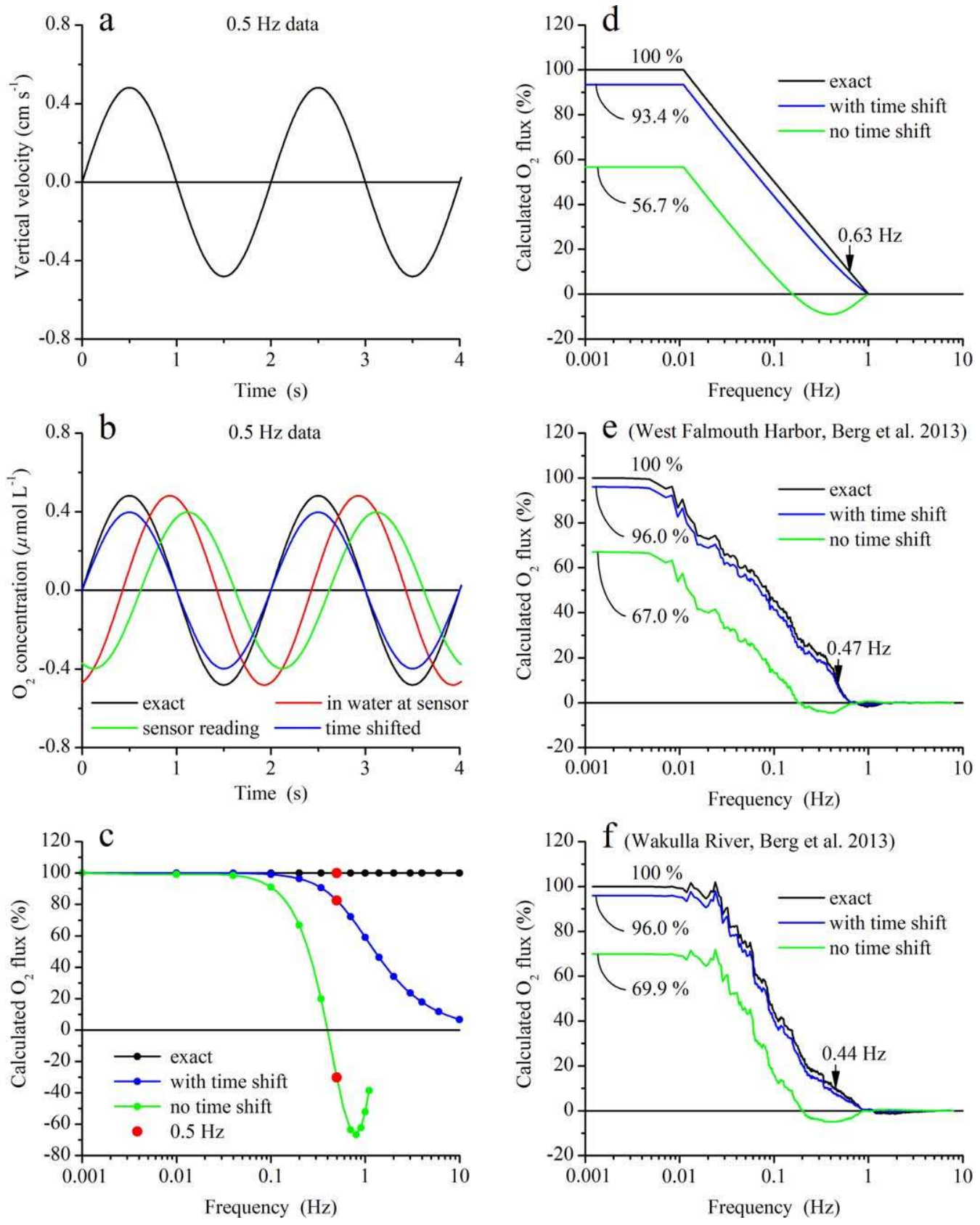

Fig. 5. Simulated oxygen signal and flux loss caused by the finite response time of the new oxygen sensor and its physical distance from the ADV. (a) Assumed $0.5 \mathrm{~Hz}$ sinusoidal fluctuation in vertical velocity. (b) Associated (identical) fluctuation in oxygen concentration at the location of the ADV (black line), at the downstream location of the oxygen sensor (red line), simulated sensor output (green line), and concentration after time shift correction (blue line). (c) Fluxes calculated from velocity and oxygen concentrations in panels a and b (red dots) and for different frequencies (black, blue, green line). The flux based on the simulated sensor output (green line) is not shown beyond $1.1 \mathrm{~Hz}$ because it began to oscillate at higher frequencies. (d) Effects of the potential signal loss on an assumed theoretical cumulative cospectrum with flux contributions in the 1-0.01 $\mathrm{Hz}$ frequency band. $10 \%$ of the total flux was associated with eddy frequencies higher than $0.63 \mathrm{~Hz}$. Initial dip of the uncorrected cumulative cospectrum (green line at $0.15-1 \mathrm{~Hz}$ ), is caused by high-frequency fluctuations in velocity and oxygen concentration that are out of phase. (e and f) Equivalent results calculated for two real cumulative cospectra measured by Berg et al. (2013).

oxygen sensitive foil, and a current flow of $7 \mathrm{~cm} \mathrm{~s}^{-1}$. The delayed concentration signal was then used as input to a simple first order response model (Bird et al. 1960) simulating the oxygen sensor output based on a $t_{90 \%}$ response time of $0.5 \mathrm{~s}$ (Fig. 3). This sensor output (Fig. 5b, green line) has slightly reduced amplitude and is also delayed further in time relative to the concentration outside the boundary layer of the sensor foil (Fig. 5b, red line). 

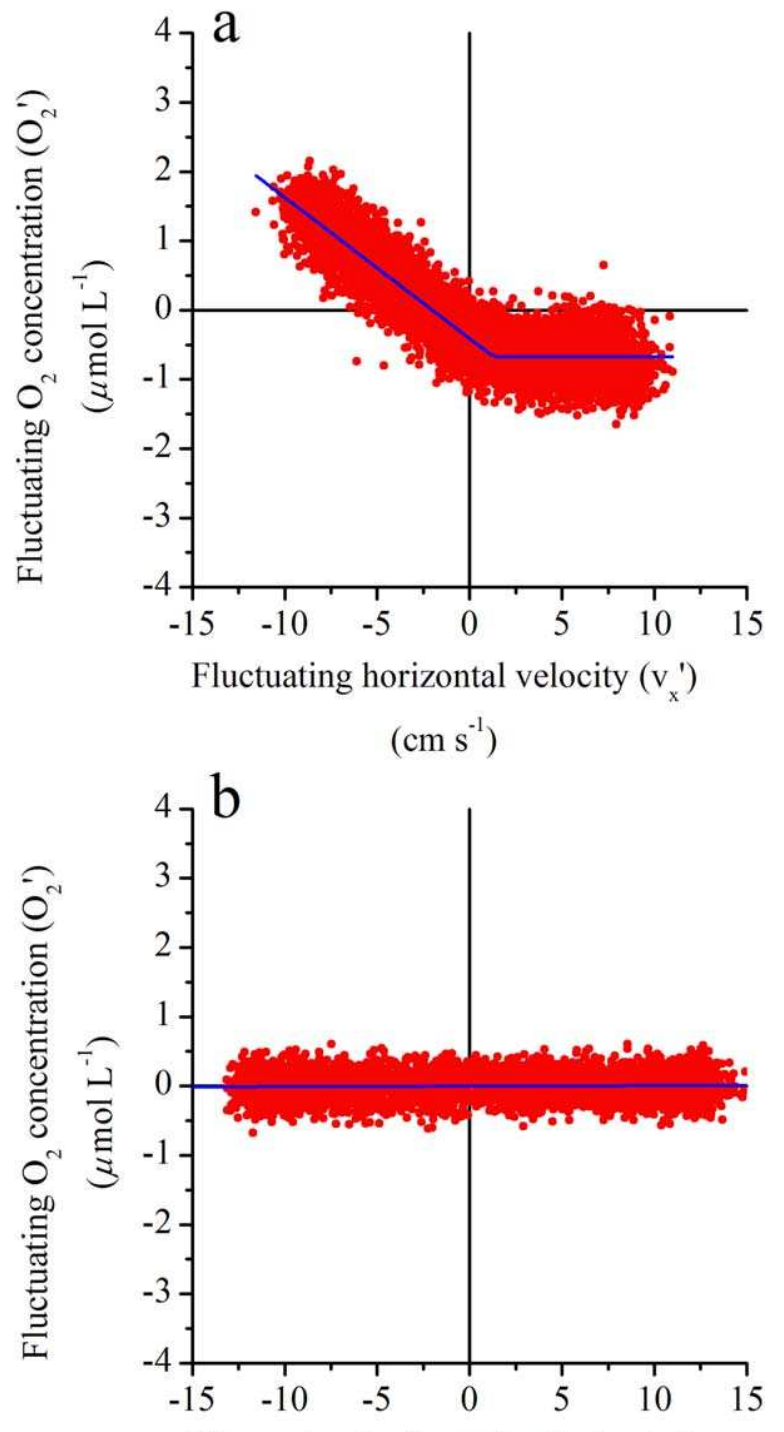

Fluctuating horizontal velocity $\left(\mathrm{v}_{\mathrm{x}}{ }^{\prime}\right)$

$$
\left(\mathrm{cm} \mathrm{s}^{-1}\right)
$$

Fig. 6. Stirring sensitivity tests in a wave tank with no concentration gradients. The oxygen concentration in the water was $270 \mu \mathrm{mol} \mathrm{L^{-1 }}$. (a) Asymmetric stirring sensitivity for a fast-responding Clark-type microelectrode. Negative velocities represent a horizontal velocity toward the electrode tip. The blue line represents a fit to the $16 \mathrm{~Hz}$ data. (b) Similar test results for the new sensor. No stirring sensitivity was identified.

From the $0.5 \mathrm{~Hz}$ fluctuating velocity (Fig. 5a) and the associated oxygen concentration at the same location (Fig. $5 \mathrm{~b}$, black line), the unbiased eddy flux was calculated and set to $100 \%$ as a reference (Fig. 5c, red dot on black line). The similar calculation, based on the simulated output from the new sensor (Fig. 5b, red dot on green line), gave a very different flux of $-30 \%$, with the reversed direction arising from the phase shift in oxygen concentration (Fig. 5b) caused by the response time of the new sensor (Fig. 3) and its physical distance from the ADV.
However, the time shift correction described above was applied to all data measured with the new sensor. This standard correction (Fan et al. 1990; McGinnis et al. 2008; Lorrai et al. 2010), which finds the maximum numeric flux, or cross-correlation between the vertical velocity and the oxygen concentration, is equivalent to a move back in time of the recorded concentration (Fig. 5b, green line) so that it becomes in phase with the velocity (Fig. 5a). Using this corrected oxygen concentration (Fig. 5b, blue line) gives a flux of $83 \%$ (Fig. 5c, red dot on blue line) that differs from the actual flux of $100 \%$ only because of the reduced amplitude of the recorded concentration. This calculation, repeated for different frequencies (Fig. 5c), showed, as expected, that the biggest loss in flux signal occurred at the high-frequencies, which are the most challenging to capture.

Because cospectra of the fluctuating vertical velocity and oxygen concentration express the eddy flux contribution as a function of frequency, they can be combined with the results in Fig. 5c to estimate how much of the total flux is lost by a system based on the new sensor. This was done for three different spectra, a theoretical one and two that were measured in our previous work. When cospectra are presented, they are usually cumulated from high toward low frequencies to remove random noise, and in the absence of wave motions, they typically show a linear-like trend within a certain frequency band (Reimers et al. 2012; Berg et al. 2013; Reidenbach et al. 2013). Hence, the theoretical cumulative cospectrum was assumed to increase linearly from $0 \%$ at $1 \mathrm{~Hz}$ to $100 \%$ at $0.01 \mathrm{~Hz}$ (Fig. 5d, black line). The associated cospectrum was then corrected with the results in Fig. 5c and cumulated to reveal that $56.7 \%$ or $93.4 \%$ of the total flux would be captured by an instrument with the new oxygen sensor depending on whether or not a time shift correction was applied (Fig. 5d, green and blue lines). Figure 5e,f show similar calculations for two real cumulative cospectra measured by Berg et al. (2013) with fast-responding Clark-type microelectrodes at shallowwater sites with high current velocities. In both cases, $96 \%$ of the flux detected using microelectrodes would be captured with the new sensor if a time shift correction is applied. All three of these cumulative cospectra have large flux contributions at high frequencies. This is noteworthy because often cospectra show only significant flux contributions for frequencies lower than $0.5 \mathrm{~Hz}$ (McGinnis et al. 2008; Lorrai et al. 2010; Reimers et al. 2012) or at times even below $0.1 \mathrm{~Hz}$ (Brand et al. 2008; Long et al. 2012).

Results from the wave tank tests, in which eddy correlation systems with a regular Clark-type microelectrode and the new sensor were exposed to varying wave velocity, are shown in Fig. 6. During these tests no consumption or production of oxygen was occurring in the wave tank, and vertical and horizontal concentration gradients were absent, therefore, any systematic variation in sensor readings are attributed to wave velocity effects. A distinct asymmetric stirring sensitivity was found for the Clark-type 

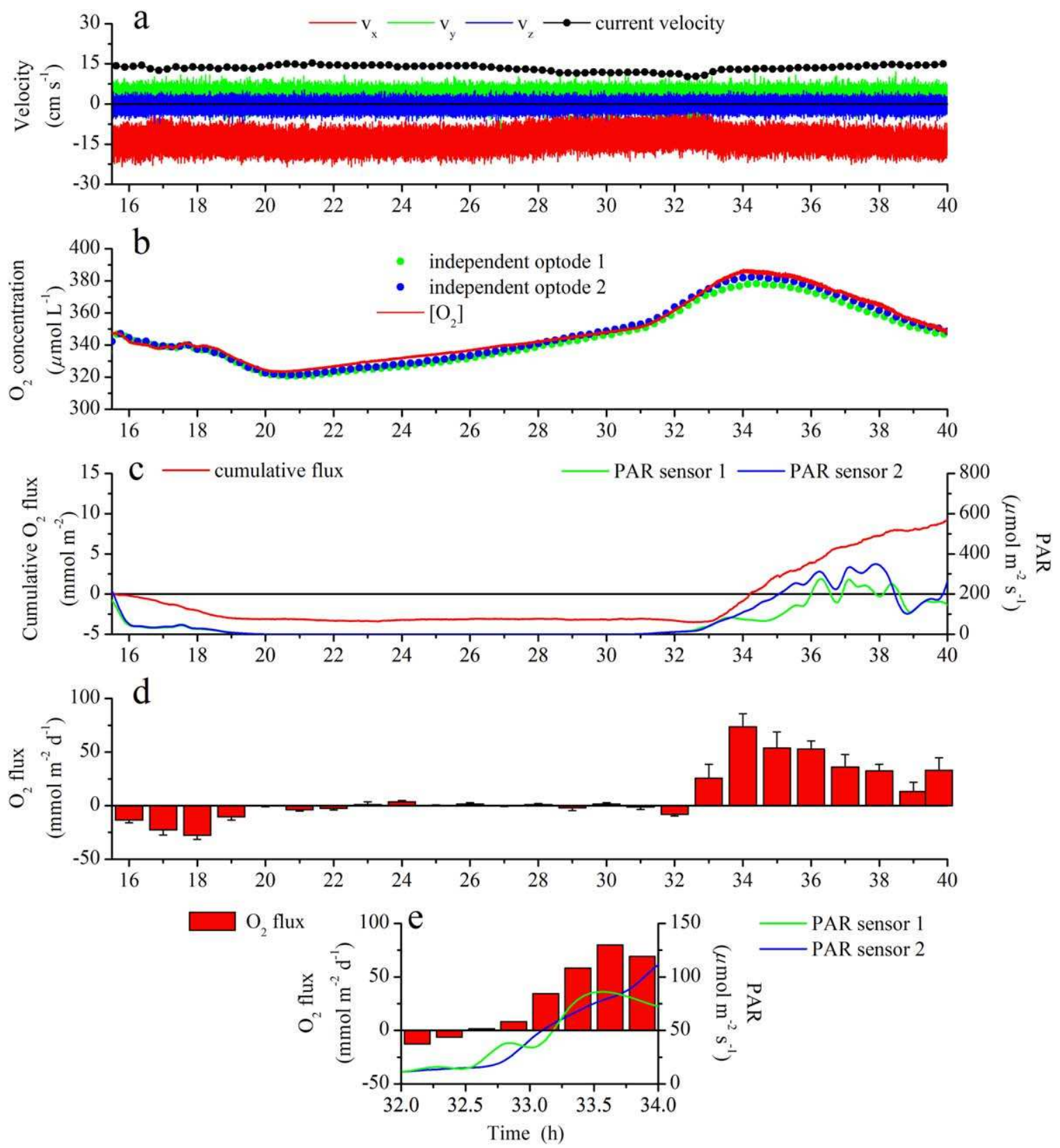

Fig. 7. Test deployment in the Hardware River, Virginia, over $24.5 \mathrm{~h}$ starting at 15:30 on 01 April 2013. (a) Three velocity components ( $x, y$, $z$ ) and 15-min mean current velocity. (b) Concentration measured with the new oxygen-temperature sensor and two independent optodes. (c) Cumulative flux and light measured by two PAR sensors. (d) Hourly fluxes, each based on 15-min flux extractions ( $n=4$, SE). Positive values represent a release of oxygen. (e) Example of 15-min fluxes and light during $2 \mathrm{~h}$ at dawn. The difference between light loggers (c and e) is caused by canopy shading.

microelectrode (Fig. 6a), while no such effect was recorded for the new sensor (Fig. 6b).

\section{Field tests}

Results from the first test deployment over $24.5 \mathrm{~h}$ in the Hardware River (Fig. 2a) are shown in Fig. 7. The current velocity (Fig. 7a) was relatively constant, averaging $13.4 \mathrm{~cm}$ $\mathrm{s}^{-1}$, whereas the oxygen concentration showed a diurnal pattern recorded by both the new sensor and the two independ- ent optodes (Fig. 7b). The diurnal cycle is reflected by the light measured with the two PAR sensors (Fig. 7c). The cumulative flux over the whole deployment (Fig. 7c) and the derived hourly fluxes (Fig. 7d) similarly showed a diurnal pattern with an oxygen uptake at dusk of $-19 \mathrm{mmol} \mathrm{m}^{-2} \mathrm{~d}^{-1}$, followed by a nighttime period with no significant flux, and then an oxygen release caused by microalga photosynthetic production after sunrise (Fig. 7e). The average flux for the daytime period at the end of the deployment (Time $>32.5 \mathrm{~h}$, 

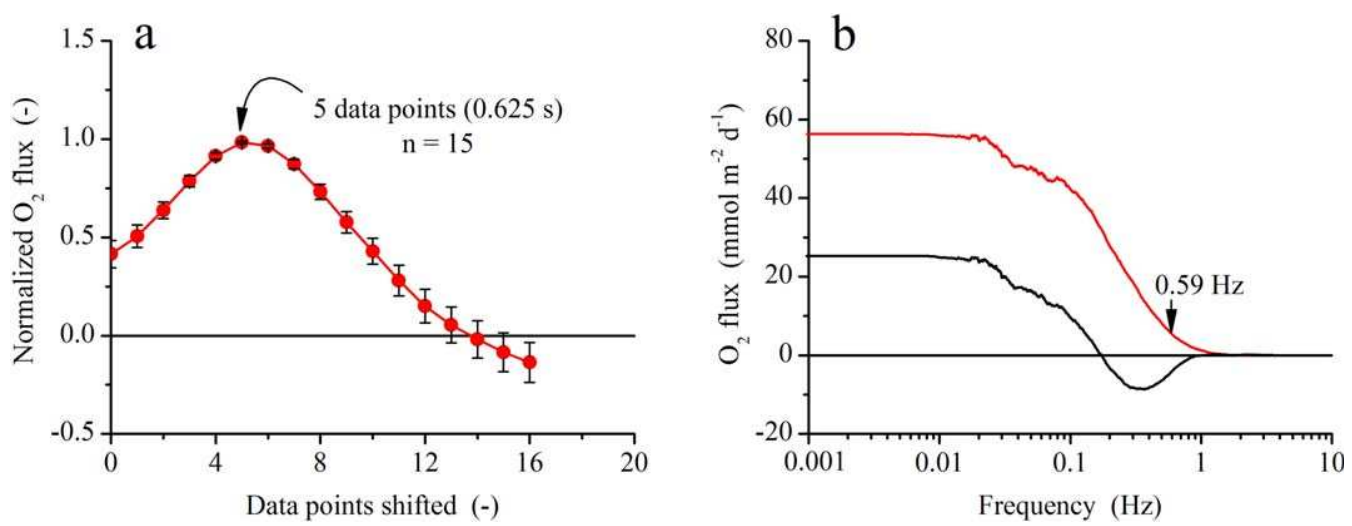

Fig. 8. (a) Average flux for different time shifts of oxygen data relative to the velocity data for the first test deployment in the Hardware River (Figs. $2 a, 7)$. The optimal time shift, here five data points, or $0.625 \mathrm{~s}$, is defined as giving the maximum numeric flux. Error bars represent SE. (b) Associated cumulative cospectra of the fluctuating vertical velocity and oxygen concentration before (black) and after (red) the time shift correction. With correction, $10 \%$ of the total captured flux was associated with eddy frequencies higher than $0.59 \mathrm{~Hz}$.

Fig. 7d) was $40 \mathrm{mmol} \mathrm{m} \mathrm{m}^{-2} \mathrm{~d}^{-1}$. The oxygen uptake at dusk, which tapered off over a few hours (Fig. 7d), was likely caused by rapid consumption of highly labile photosynthates produced during the daytime (Glud 2008), whereas the succeeding zero nighttime flux suggests that other pools of labile organic matter in the permeable river bed were not available.

This deployment revealed that the new sensor recorded low-noise concentrations with no abnormalities (e.g., spikes and jumps) as are often seen in Clark-type microelectrode data (Berg et al. 2013). Such abnormalities are caused by floating debris hitting the electrode and require careful data quality checks and clean up before fluxes can be extracted (Berg et al. 2013). This process is often time consuming, generates gaps in the flux record, and adds uncertainties. No data were removed from the $24.5 \mathrm{~h}$ long concentration record measured with the new sensor (Fig. 7b).

The analysis identifying the optimal time shift applied to the Hardware River data (Fig. 7) is shown in Fig. 8. An optimal time shift of five data points, or $0.625 \mathrm{~s}$ at $8 \mathrm{~Hz}$ data resolution (Fig. 8a), was found for a period at dawn, from $33 \mathrm{~h}$ to $36.75 \mathrm{~h}$, with a substantial flux signal in the data. This time shift was then applied to the entire concentration record. The cumulative cospectrum without time shift correction (Fig. 8b) shows the characteristic drop in flux contribution when moving from higher toward lower frequencies indicating that a correction is required (Berg et al. 2013), which is fully in line with the evaluation above (Fig. 5d-f). In the cumulative cospectrum (Fig. 8b) the $0.59 \mathrm{~Hz}$ mark, where $10 \%$ of the total flux was accounted for when moving from higher toward lower frequencies, shows that the new sensor is capable of capturing high-frequency fluctuations. For comparison, similar frequency thresholds in measurements with Clark-type microelectrode based systems were $0.47 \mathrm{~Hz}$ and $0.44 \mathrm{~Hz}$ for sites that also had substantial highfrequency flux contributions (Fig. 5e,f).
Results of similar quality were obtained in two additional deployments in the Hardware River, which confirmed the robustness of the new sensor. Key results for all deployments are summarized in Table 1.

For all of the Hardware River deployments, the mean current velocity was $16.0 \pm 1.6 \mathrm{~cm} \mathrm{~s}^{-1}(n=3, \mathrm{SE})$ and the averaged optimal time shift was $0.83 \pm 0.19 \mathrm{~s}(n=3, \mathrm{SE})$. With a distance of $1.5 \mathrm{~cm}$ between the edge of the ADV's measuring volume and the edge of the sensor tip (Fig. 1), the distance between the "measuring points" of the two was assessed to be $2.5 \mathrm{~cm}$. This distance translates to a time delay of $0.16 \mathrm{~s}$, which, when added to the measured response time $\left(t_{90 \%}\right)$ of the new sensor (Fig. 3), gives a delay of 0.77 s. The averaged optimal time shift of $0.83 \mathrm{~s}$ is close to this delay, which supports that the equilibration time through the boundary layer flow that forms over the oxygen sensitive foil (Fig. 1) is marginal, as argued above.

Results similar to those in Fig. 8, but for the heat flux, are shown in Fig. 9 for the second test deployment in the Hardware River (Table 1). The optimal time shift was found to be four data points, or $0.5 \mathrm{~s}$ (Fig. 9a). The $0.61 \mathrm{~Hz}$ mark (Fig. $9 b)$, where $10 \%$ of the total flux was accounted for, indicates that the thermistor is capable of capturing high-frequency fluctuations as well.

For all of the Hardware River deployments, the averaged optimal time shift for the heat flux was $0.67 \pm 0.16 \mathrm{~s}(n=3$, SE), which is only slightly smaller than that of $0.83 \pm 0.19 \mathrm{~s}$ $(n=3$, SE) found for oxygen. Additionally, the average frequency thresholds, in which $10 \%$ of the total flux was accounted for (Figs. 8b, 9b), were remarkably similar, equaling $0.51 \pm 0.08 \mathrm{~s}(n=3, \mathrm{SE})$ for oxygen and $0.49 \pm 0.13 \mathrm{~s}$ $(n=3, \mathrm{SE})$ for heat. These similarities suggest that the oxygen optode and adjacent thermistor were equally capable of capturing high-frequency fluctuations and producing realistic fluxes, provided that the time shift correction is applied. 
Table 1. Key results for all test deployments. The oxygen sensitive foil was attached to the new sensor with electrical tape in all deployments except for deployment 5 (see text for details). The numbers in parentheses (deployment 5) are for the system based on a Clark-type microelectrode deployed concurrently with the system carrying the new sensor.

\begin{tabular}{|c|c|c|c|c|c|c|c|c|}
\hline 1 & Hardware River & 01-02 Apr 2013 & 24.5 & 13.4 & 0.625 & 1.000 & 0.59 & 0.23 \\
\hline 2 & Hardware River & 21-22 Jun 2013 & 24.5 & 18.9 & 0.875 & 0.500 & 0.59 & 0.61 \\
\hline 5 & Florida Keys & 16-17 Aug 2013 & $20.9(2.0)$ & 7.4 & 1.750 & 2.125 & $0.21(0.24)$ & 0.22 \\
\hline
\end{tabular}

${ }^{*} 10 \%$ of the total captured oxygen flux was associated with higher eddy frequencies, see Figs. 8,12 .

** $10 \%$ of the total captured heat flux was associated with higher eddy frequencies, see Fig. 9.

Results of the first test deployment in the Florida Keys over 10 nighttime hours are shown in Fig. 10. The current velocity (Fig. 10a) varied from $2.5 \mathrm{~cm} \mathrm{~s}^{-1}$ to $13.9 \mathrm{~cm} \mathrm{~s}^{-1}$ with an average of $7.6 \mathrm{~cm} \mathrm{~s}^{-1}$, whereas the oxygen concentration was close-to-constant with small short-lived variations detected by both the new sensor and the independent optode (Fig. 10b). The cumulative flux over the whole deployment (Fig. 10c) and also the derived 15-min fluxes (Fig. 10d) showed oxygen uptake throughout the night with an average of $-31 \mathrm{mmol} \mathrm{m} \mathrm{m}^{-2} \mathrm{~d}^{-1}$. The 15 -min fluxes indicated a dependency of the fluxes on current velocity (Fig. 10e), with $\mathrm{a} \sim 2$-5-fold increase in oxygen uptake over the range of measured current velocity. This stimulation of oxygen consumption by flow is in line with earlier eddy covariance studies in permeable sandy sediments (Berg and Huettel 2008; Berg et al. 2013; McGinnis et al. 2014).

Also, in this marine deployment, the new sensor performed flawlessly and no data were removed from the $10 \mathrm{~h}$ long data record (Fig. 10b). The larger distance between the edge of the ADV's measuring volume and the edge of the new sensor's tip $(2-2.5 \mathrm{~cm})$ combined with the smaller current velocity, explain the larger time shift of $1.25 \mathrm{~s}$ relative to those found in the Hardware River (Table 1).

Results of the second test deployment with two eddy covariance instruments (Fig. 2b) in the Florida Keys over 2 daytime hours are shown in Fig. 11. High quality oxygen data were recorded by both systems until $2 \mathrm{~h}$ into the deployment when the microelectrode broke (Fig. 11b), whereas the new sensor recorded data for the full $20.9 \mathrm{~h}$ deployment time (data not shown). The light level (Fig. 11d), was adequate to give an oxygen release from the permeable sand caused by photosynthetic production as reflected in both the steadily climbing cumulative fluxes (Fig. 11c) and also in the positive 15-min fluxes (Fig. 11d). Averaged over the $2 \mathrm{~h}$, where both systems were working, the oxygen release captured by the system with a regular microelectrode was $65 \pm 5 \mathrm{mmol} \mathrm{m} \mathrm{m}^{-2} \mathrm{~d}^{-1}(n=8$, SE) and $71 \pm 8 \mathrm{mmol} \mathrm{m}^{-2} \mathrm{~d}^{-1}(n=8, \mathrm{SE})$ for the system with the new sensor (Fig. 11e). The two fluxes are not significantly different (two sample $t$-test, $n=8, p=0.01$ ).
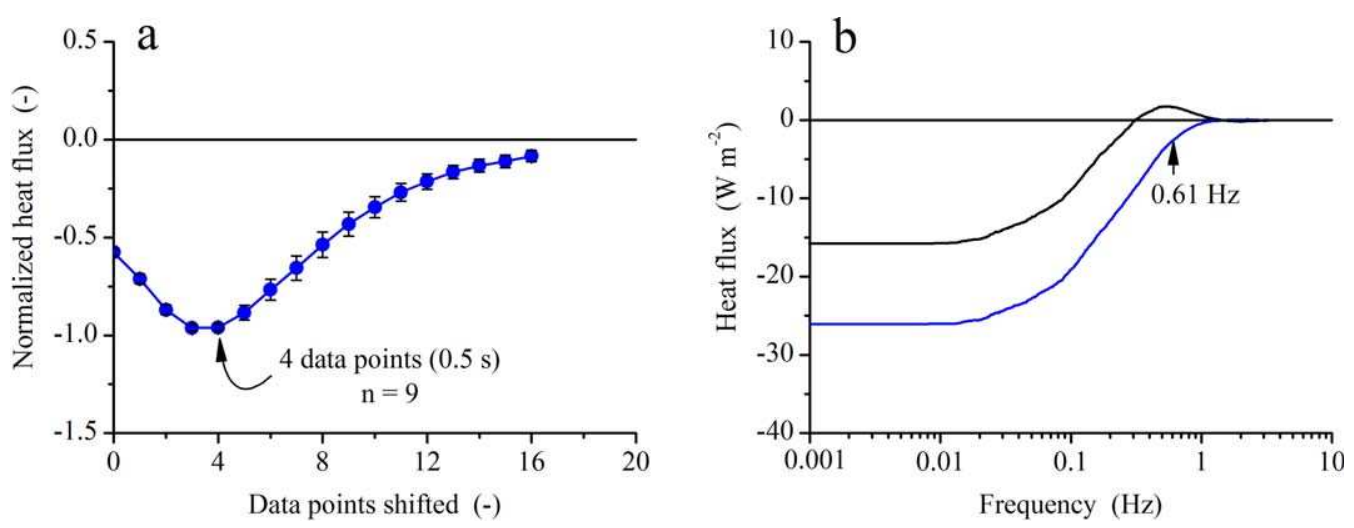

Fig. 9. (a) Average flux for different time shifts of temperature data relative to the velocity data for the second test deployment in the Hardware River. (b) Associated cumulative cospectra of the fluctuating vertical velocity and temperature before (black) and after (blue) the time shift correction. See Fig. 8 for further explanation. 

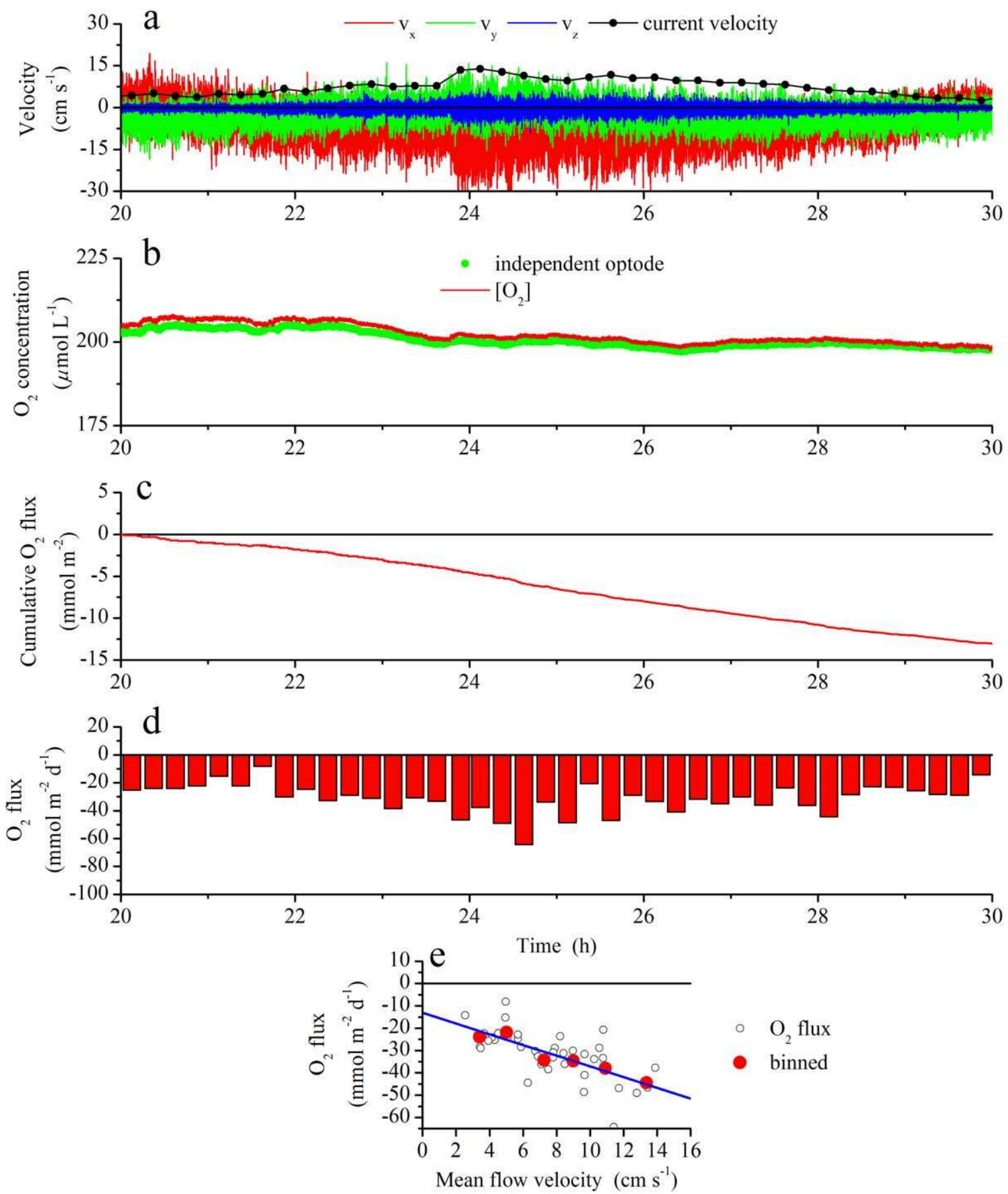

Fig. 10. Nighttime deployment in the Florida Keys over $10 \mathrm{~h}$ starting at 20:00 on 12 August 2013. (a) Three velocity components ( $x, y, z)$ and 15 min mean current velocity. (b) Oxygen concentration measured with the new sensor and one independent optode. (c) Cumulative flux with clear linear trend. (d) 15-min fluxes. Negative values represent an uptake of oxygen. (e) Relationship between 15-min oxygen fluxes and current velocities (open circles). Binned data (red dots) are shown to illustrate the relationship.

The cumulative cospectra of the fluctuating vertical velocity and oxygen concentration from the second deployment in the Florida Keys (Fig. 11) are shown in Fig. 12. The time shift corrected spectrum for the new sensor agrees with that for the Clark-type microelectrode in terms of shape and characteristics. For example, both spectra include a small flux contribution from wave action seen in the $0.2-0.3 \mathrm{~Hz}$ frequency band and they have the same slope for frequencies below this band. Also, the frequency thresholds of $0.21 \mathrm{~Hz}$ and $0.24 \mathrm{~Hz}$, respectively, where $10 \%$ 

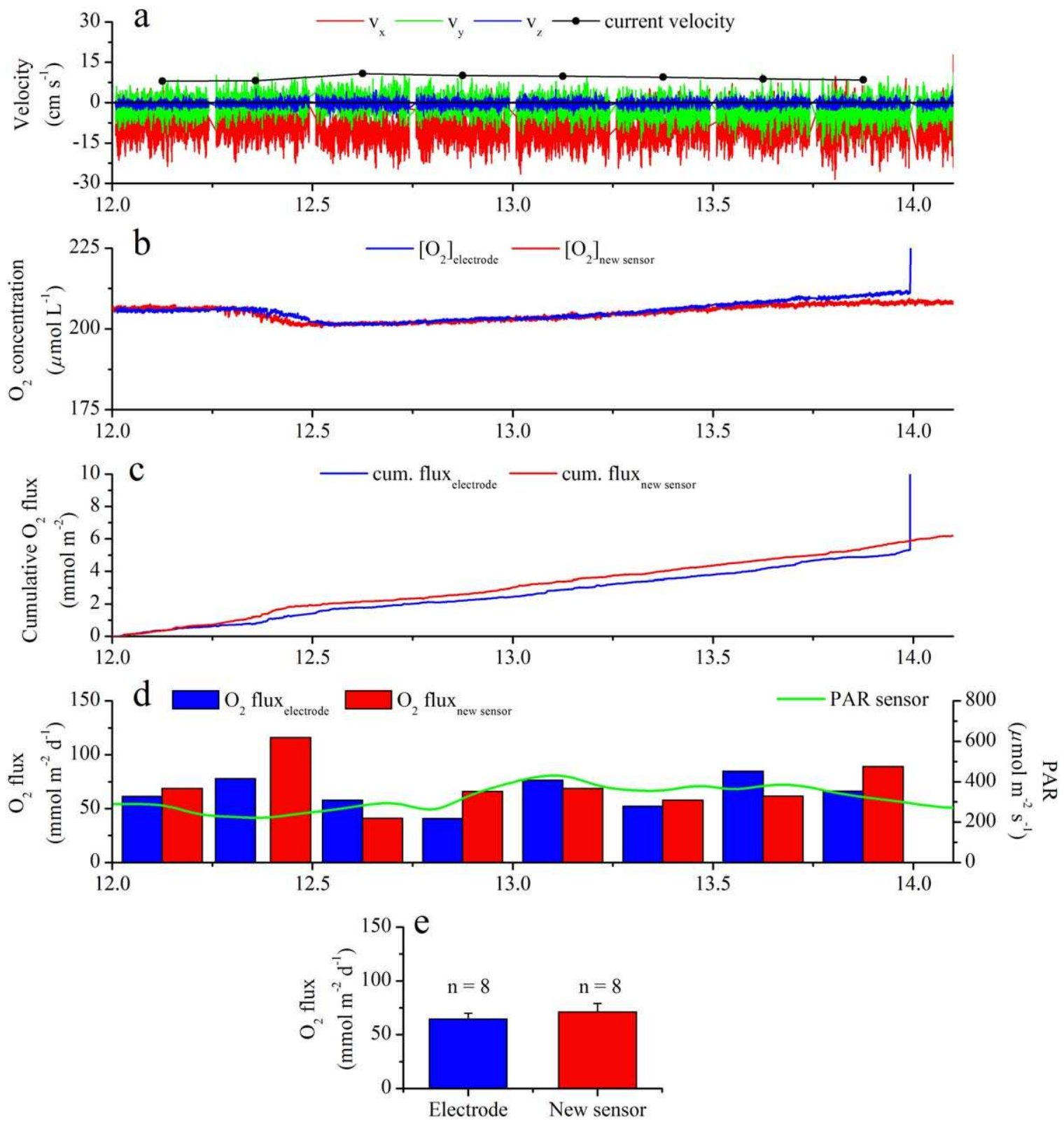

Fig. 11. Daytime deployment (12:00-14:00) with two eddy covariance systems, one with a Clark-type microelectrode and one with the new sensor (Fig. 2b) in the Florida Keys on 16 August 2013. (a) Three velocity components $(x, y, z)$ and 15-min mean current velocity. (b) Oxygen concentrations measured with a microelectrode and the new sensor. The former broke after $2 \mathrm{~h}$. (c) Cumulative fluxes with clear linear and almost identical trends for both systems. (d) 15-min fluxes from the two systems, and light (PAR) measured at the bottom. (e) Averaged fluxes measured with the two systems.

of the total flux was accounted for, were practically the same.

In this last deployment, the new sensor's plastic disc with sensor foil was held in place with a small plastic cap instead of PVC tape. This difference likely explains the larger time shifts (1.75 vs. $1.25 \mathrm{~s}$ for oxygen and 2.125 vs. 0.625 for temperature, Table 1). Subsequently, the sensor design was changed based on these test results so that the disc is now fastened to the sensor stem with double sided adhesive tape. The two small titanium pins at the end of the stem fit into two holes in each disc to ensure correct and consistent positioning when discs are replaced, an operation that is easily performed by a user. Based on our use of the new sensor, we assess the lifetime of the foil due to photobleaching before a disc must be replaced is on the order of 1-2 weeks of continuous use. 


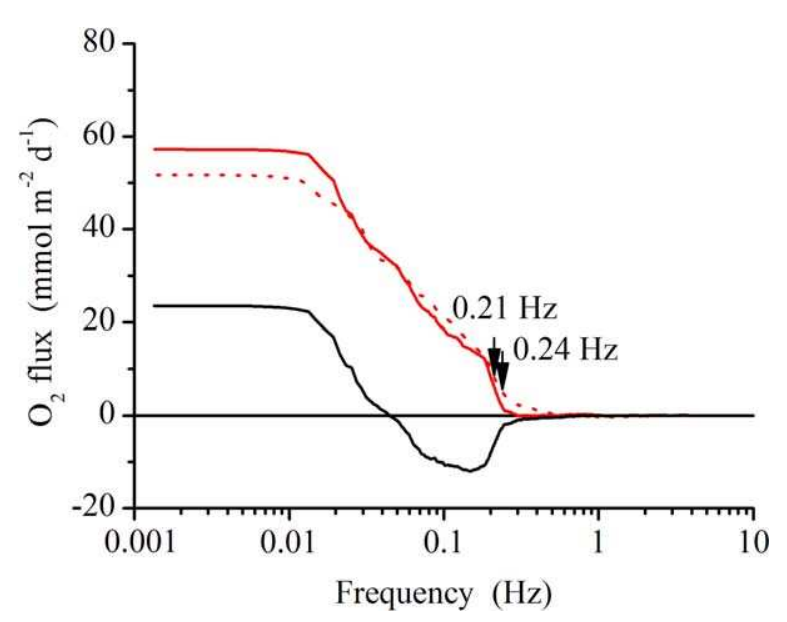

Fig. 12. Cumulative cospectra covering the $2 \mathrm{~h}$ test deployment in the Florida Keys (Fig. 11) for the system with Clark-type microelectrode (dashed red line) and the system with the new sensor (solid red line). Black line represents the uncorrected cumulative cospectrum of the dataset generated with the new sensor.

\section{Discussion}

The test results demonstrate that the new dual oxygentemperature sensor (Figs. 1,2) can be a viable alternative to the commonly used fragile Clark-type microelectrodes for aquatic eddy covariance measurements of oxygen fluxes. In all deployments with the new sensor, it consistently gave high-quality data with low noise levels and with no spikes and jumps (Figs. 7, 10, 11) as are sometimes found in data measured with Clark-type microelectrodes. Without such abnormalities, manual data quality checks and clean up before fluxes are calculated can be significantly reduced. A further benefit of the new sensor is that it did not show any stirring sensitivity in our tests (Fig. 6). Two new studies indicate that stirring sensitivity may affect eddy flux extractions from some data measured with microelectrodes in unidirectional flows (Holtappels et al. 2015) and in wave environments (Reimers et al. Accepted).

Also, the new sensor allows concurrent heat flux measurements, which can be used to ground-truth oxygen flux measurements and to assess groundwater seepage (Crusius et al. 2008) or sea-ice melt rates (Long et al. 2012). Finally, the reliability of the sensor and the high quality of data it produces generates new opportunities for eddy covariance flux studies, including long-term deployments in rivers, streams, and marine environments (Berg et al. 2013; Koopmans and Berg 2015).

However, the new sensor's response time and tip size require special care during its deployment and also when fluxes are extracted.

The response times $\left(t_{90 \%}\right)$ are $0.51 \mathrm{~s}$ for oxygen and $0.34 \mathrm{~s}$ for temperature (Fig. 3). In addition, the sensor tip, due to its size, must be positioned at a greater distance from the ADV's measuring volume than smaller micro-sensors. The response time, combined with this larger distance, requires that a time shift correction (Fan et al. 1990; McGinnis et al. 2008; Lorrai et al. 2010) is applied to all data measured with the new sensor. This is clearly confirmed by all oxygen flux calculations from this study (Figs. 5, 8, 12) and also by those for the associated heat fluxes (Fig. 9). With time shift correction, the new sensor captures high-frequency flux contributions equally well as microelectrodes as indicated by the high-frequency thresholds in our cospectra, where $10 \%$ of the total flux was accounted for (Figs. 5, 8, 12). This reassuring performance was further supported by the statistically identical oxygen fluxes measured by the two side-by-side eddy covariance instruments deployed in the Florida Keys, one with a traditional microelectrode and one with the new sensor (Figs. 11, 12).

Furthermore, due to the new sensor's relatively large tip (Figs. 1, 2), it should not be positioned directly upstream from the ADV's measuring volume as it may affect the velocity measurements. While deployments in the Hardware River showed that sensor orientation perpendicular to the current direction did not result in significantly different oxygen fluxes, deployments over dense seagrass meadows suggested that flux reductions sometimes, but not always, arose when the sensor pointed downstream (data not shown). While these results were not conclusive, we recommend, as a conservative precaution, that the new sensor is positioned facing up into the current when seen from above within $\mathrm{a} \pm 60^{\circ}$ window. At sites with changing flow directions (e.g., tidal environments), this requirement will evidently lead to exclusion of otherwise highquality data. However, this disadvantage should be weighed against the loss of useful data that is inherently associated with using more fragile sensor technologies.

\section{Comments and recommendations}

This detailed evaluation of the new dual oxygentemperature sensor for aquatic eddy covariance measurements points to some clear advantages over the commonly used Clark-type microelectrodes, and to some limitations that must be addressed during deployment planning and flux extractions. As a result, we do not see the new sensor as a replacement for microelectrodes, but rather as a viable alternative in some marine and freshwater environments.

Other sensor solutions are currently being developed; for example, thin optical fiber sensors, with tip sizes of 100-400 $\mu \mathrm{m}$, have shown promising performances in eddy covariance measurements (Chipman et al. 2012; Kreling et al. 2014; Long et al. 2015b). Our ongoing tests of this solution have shown that optical fiber sensors are more robust than Clarktype electrodes and result on average in longer successful data recordings, but they are still vulnerable to signal disturbances or breakage by impact with filamentous algae, seagrass blades, or other naturally occurring debris (M. Huettel unpubl.). Furthermore, other tests surprisingly suggest that optical fiber sensors can be stirring sensitive, as Clark-type 
electrodes, for reasons we cannot yet explain (D. Koopmans unpubl.). More tests of this and other sensor solutions are highly warranted.

In summary, we expect that the development of new sensor solutions for aquatic eddy covariance measurements will continue. This, along with advances in flux extraction procedures for non-perfect field conditions, will lead to a much wider use of the eddy covariance technique as the only approach that can measure benthic fluxes at high temporal resolution without disturbing key environmental parameters controlling these fluxes.

\section{References}

Attard, K. M., G. N. Glud, D. F. McGinnis, and S. Rysgaard. 2014. Seasonal rates of benthic primary production in a Greenland fjord measured by aquatic eddy correlation. Limnol. Oceanogr. 59: 1555-1569. doi:10.4319/ lo.2014.59.5.1555

Attard, K. M., H. Stahl, N. A. Kamenos, G. Turner, H. L. Burdett, and R. N. Glud. 2015. Benthic oxygen exchange in a live coralline algal bed and an adjacent sandy habitat: An eddy covariance study. Mar. Ecol. Prog. Ser. 535: 99115. doi:10.3354/meps11413

Aubinet, M., T. Vesala, and D. Papale. 2012. Eddy covariance: A practical guide to measurement and data analysis. Springer.

Baldocchi, D. D. 2003. Assessing the eddy covariance technique for evaluating carbon dioxide exchange rates of ecosystems: Past, present and future. Glob. Change Biol. 9: 479-492. doi:10.1046/j.1365-2486.2003.00629.x

Berg, P., H. Roy, F. Janssen, V. Meyer, B. B. Jorgensen, M. Huettel, and D. de Beer. 2003. Oxygen uptake by aquatic sediments measured with a novel non-invasive eddy-correlation technique. Mar. Ecol. Prog. Ser. 261: 75-83. doi: 10.3354/meps261075

Berg, P., H. Roy, and P. L. Wiberg. 2007. Eddy correlation flux measurements: The sediment surface area that contributes to the flux. Limnol. Oceanogr. 52: 1672-1684. doi:10.4319/10.2007.52.4.1672

Berg, P., and M. Huettel. 2008. Monitoring the seafloor using the noninvasive eddy correlation technique: Integrated benthic exchange dynamics. Oceanography 21: 164-167. doi:10.5670/oceanog.2008.13

Berg, P., R. N. Glud, A. Hume, H. Stahl, K. Oguri, V. Meyer, and H. Kitazato. 2009. Eddy correlation measurements of oxygen uptake in deep ocean sediments. Limnol. Oceanogr.: Methods 7: 576-584. doi:10.4319/lom.2009.7.576

Berg, P., and others. 2013. Eddy correlation measurements of oxygen fluxes in permeable sediments exposed to varying current flow and light. Limnol. Oceanogr. 58: 1329-1343. doi:10.4319/1o.2013.58.4.1329

Bird, R. B., W. E. Slewart, and E. N. Lightfoot. 1960. Transport phenomena. John Wiley.
Brand, A., D. F. McGinnis, B. Wehrli, and A. Wüest. 2008. Intermittent oxygen flux from the interior into the bottom boundary of lakes as observed by eddy correlation. Limnol. Oceanogr. 53: 1997-2006. doi:10.4319/lo.2008.53.5.1997

Burba, G. 2013. Eddy covariance method for scientific, industrial, agricultural, and regulatory applications: A field book on measuring ecosystem gas exchange and areal emission rates, p. 331. LI-COR Biosciences.

Canfield, D. E., and others. 1993. Pathways of organic carbon oxidation in three continental margin sediments. Mar. Geol. 113: 27-40. doi:10.1016/0025-3227(93)90147-N

Cathalot, C., D. Van Oevelen, T. Cox, T. Kutti, M. Lavaleye, G. Duineveld, and F. J. Meysman. 2015. Cold-water coral reefs and adjacent sponge grounds: Hotspots of benthic respiration and organic carbon cycling in the deep sea. Front. Mar. Sci. 2: 37. doi:10.3389/fmars.2015.00037

Chipman, L., M. Huettel, P. Berg, V. Meyer, I. Klimant, R. Glud, and F. Wenzhoefer. 2012. Oxygen optodes as fast sensors for eddy correlation measurements in aquatic systems. Limnol. Oceanogr.: Methods 10: 304-316. doi: 10.4319/lom.2012.10.304

Cook, P. L. M., F. Wenzhofer, R. N. Glud, F. Janssen, and M. Huettel. 2007. Benthic solute exchange and carbon mineralization in two shallow subtidal sandy sediments: Effect of advective pore-water exchange. Limnol. Oceanogr. 52: 1943-1963. doi:10.4319/lo.2007.52.5.1943

Crusius, J., P. Berg, D. J. Koopmans, and L. Erban. 2008. Eddy correlation measurements of submarine groundwater discharge. Mar. Chem. 109: 77-85. doi:10.1016/ j.marchem.2007.12.004

Fan, S. M., S. C. Wofsy, P. S. Bakwin, D. J. Jacob, and D. R. Fitzjarrald. 1990. Atmosphere-biosphere exchange of CO2 and $\mathrm{O} 3$ in the central Amazon forest. J. Geophys. Res. Atmos. 95: 16851-16864. doi:10.1029/JD095iD10p16851

Glud, R. N. 2008. Oxygen dynamics of marine sediments. Mar. Biol. Res. 4: 243-289. doi:10.1080/17451000801888726

Glud, R. N., P. Berg, A. Hume, P. Batty, M. E. Blicher, K. Lennert, and S. Rysgaard. 2010. Benthic O-2 exchange across hard-bottom substrates quantified by eddy correlation in a sub-Arctic fjord. Mar. Ecol. Prog. Ser. 417: 1-12. doi:10.3354/meps08795

Gundersen, J. K., and B. B. Jørgensen. 1990. Microstructure of diffusive boundary layers and the oxygen uptake of the sea floor. Nature 345: 604-607. doi:10.1038/345604a0

Hall, R. O., S. Thomas, and E. E. Gaiser [eds.]. 2007. Measuring primary production and respiration in freshwater ecosystems. Oxford Univ. Press.

Holst, G., R. N. Glud, M. Kuhl, and I. Klimant. 1997. A microoptode array for fine-scale measurement of oxygen distribution. Sens. Actuators B Chem. 38: 122-129. doi: 10.1016/S0925-4005(97)80181-5

Holst, G., O. Kohls, I. Klimant, B. Konig, M. Kuhl, and T. Richter. 1998. A modular luminescence lifetime imaging system for mapping oxygen distribution in biological 
samples. Sens. Actuators B Chem. 51: 163-170. doi: 10.1016/S0925-4005(98)00232-9

Holtappels, M., C. Noss, K. Hancke, C. Cathalot, D. McGinnis, A. Lorke, and R. N. Glud. 2015. Aquatic eddy correlation: Quantifying the artificial flux caused by stirring sensitive $\mathrm{O} 2$ sensors. Plos One 10: e0116564. doi: 10.1371/journal.pone.0116564

Holtgrieve, G. W., D. E. Schindler, T. A. Branch, and Z. T. A'Mar. 2010. Simultaneous quantification of aquatic ecosystem metabolism and reaeration using a Bayesian statistical model of oxygen dynamics. Limnol. Oceanogr. 55: 1047-1063. doi:10.4319/1o.2010.55.3.1047

Hume, A. C., P. Berg, and K. J. McGlathery. 2011. Dissolved oxygen fluxes and ecosystem metabolism in an eelgrass (Zostera marina) meadow measured with the eddy correlation technique. Limnol. Oceanogr. 56: 86-96. doi: 10.4319/1o.2011.56.1.0086

Jørgensen, B. B., and N. P. Revsbech. 1985. Diffusive boundary layers and the oxygen uptake of sediments and detritus. Limnol. Oceanogr. 30: 111-122. doi:10.4319/ lo.1985.30.1.0111

Klimant, I., V. Meyer, and M. Kuehl. 1995. Fiber-optic oxygen microsensors, a new tool in aquatic biology. Limnol. Oceanogr. 40: 1159-1165. doi:10.4319/lo.1995.40.6.1159

Koopmans, D. J., and P. Berg. 2015. Stream oxygen flux and metabolism determined with the open water and aquatic eddy covariance techniques. Limnol. Oceanogr. 60: 13441355. doi:10.1002/lno.10103

Kreling, J., J. Bravidor, D. F. McGinnis, M. Koschorreck, and A. Lorke. 2014. Physical controls of oxygen fluxes at pelagic and benthic oxyclines in a lake. Limnol. Oceanogr. 59: 1637-1650. doi:10.4319/lo.2014.59.5.1637

Kuwae, T., K. Kamio, T. Inoue, E. Miyoshi, and Y. Uchiyama. 2006. Oxygen exchange flux between sediment and water in an intertidal sandflat, measured in situ by the eddycorrelation method. Mar. Ecol. Prog. Ser. 307: 59-68. doi: 10.3354/meps307059

Lee, X., W. Massman, and B. Law. 2004. Handbook of micrometeorology: A guide for surface flux measurement and analysis. Kluwer Academic Publishers.

Lin, C. S., R. W. Moulton, and G. L. Putnam. 1953. Mass transfer between solid wall and fluid streams-mechanism and eddy distribution relationships in turbulent flow. Ind. Eng. Chem. 45: 636-640. doi:10.1021/ ie50519a600

Long, M. H., D. Koopmans, P. Berg, S. Rysgaard, R. N. Glud, and D. H. Søgaard. 2012. Oxygen exchange and ice melt measured at the ice-water interface by eddy correlation. Biogeosciences 9: 1957-1967. doi:10.5194/bg-9-19572012

Long, M. H., P. Berg, D. de Beer, and J. C. Zieman. 2013. In situ coral reef oxygen metabolism: An eddy correlation study. Plos One 8: e58581. doi:10.1371/journal.pone. 0058581
Long, M. H., P. Berg, K. M. McGlathery, and J. C. Zieman. 2015a. Sub-tropical seagrass ecosystem metabolism measured by eddy correlation. Mar. Ecol. Prog. Ser. 529: 7590. doi:10.3354/meps11314

Long, M. H., M. A. Charette, W. R. Martin, and D. C. McCorkle. 2015b. Oxygen metabolism and $\mathrm{pH}$ in coastal ecosystems: Eddy covariance hydrogen ion and oxygen exchange system (ECHOES). Limnol. Oceanogr.: Methods 13: 438-450. doi:10.1002/lom 3.10038

Lorke, A., D. F. McGinnis, and A. Maeck. 2013. Eddy-correlation measurements of benthic fluxes under complex flow conditions: Effects of coordinate transformations and averaging time scales. Limnol. Oceanogr.: Methods 11: 425-437. doi:10.4319/lom.2013.11.425

Lorrai, C., D. F. McGinnis, P. Berg, A. Brand, and A. Wüest. 2010. Application of oxygen eddy correlation in aquatic systems. J. Atmos. Ocean. Technol. 27: 1533-1546. doi: 10.1175/2010JTECHO723.1

McGinnis, D. F., P. Berg, A. Brand, C. Lorrai, T. J. Edmonds, and A. Wüest. 2008. Measurements of eddy correlation oxygen fluxes in shallow freshwaters: Towards routine applications and analysis. Geophys. Res. Lett. 35: L04403. doi:10.1029/2007GL032747

McGinnis, D. F., S. Sommer, A. Lorke, R. N. Glud, and P. Linke. 2014. Quantifying tidally driven benthic oxygen exchange across permeable sediments: An aquatic eddy correlation study. J. Geophys. Res. Oceans 119: 69186932. doi:10.1002/2014JC010303

Murniati, E., S. Geissler, and A. Lorke. 2015. Short-term and seasonal variability of oxygen fluxes at the sedimentwater interface in a riverine lake. Aquat. Sci. 77: 183-196. doi:10.1007/s00027-014-0362-7

Odum, H. T. 1956. Primary production in flowing waters. Limnol. Oceanogr. 1: 103-117. doi:10.4319/1o.1956.1.2.0102

Raymond, P., and J. Cole. 2001. Gas exchange in rivers and estuaries: Choosing a gas transfer velocity. Estuaries 24: 312-317. doi:10.2307/1352954

Raymond, P. A., and others. 2012. Scaling the gas transfer velocity and hydraulic geometry in streams and small rivers. Limnol. Oceanogr.: Fluids Environ. 2: 41-53. doi: 10.1215/21573689-1597669

Reidenbach, M. A., P. Berg, A. Hume, J. C. Hansen, and E. R. Whitman. 2013. Hydrodynamics of intertidal oyster reefs: The influence of boundary layer flow processes on sediment and oxygen exchange. Limnol. Oceanogr.: Fluids Environ. 3: 225-239. doi:10.1215/215736892395266

Reimers, C. E., T. Özkan-Haller, A. Albright, and P. Berg. Accepted. Microelectrode velocity effects and aquatic eddy covariance measurements under waves. Journal of Atmospheric and Oceanic Technology.

Reimers, C. E., T. Özkan-Haller, P. Berg, A. Devol, K. McCann-Grosvenor, and R. D. Sanders. 2012. Benthic oxygen consumption rates during hypoxic conditions on 
the Oregon continental shelf: Evaluation of the eddy correlation method. J. Geophys. Res. 117: 1-18. doi:10.1029/ 2011JC007564

Rheuban, J. E., P. Berg, and K. J. McGlathery. 2014. Multiple timescale processes drive ecosystem metabolism in eelgrass (Zostera marina) meadows. Mar. Ecol. Prog. Ser. 507: 1-13. doi:10.3354/meps10843

Rovelli, L., and others. 2015. Benthic O2 uptake of two coldwater coral communities estimated with the non-invasive eddy-correlation technique. Mar. Ecol. Prog. Ser. 525: 97104. doi:10.3354/meps11211

Schlichting, H. 1979. Boundary layer theory, 7th ed. McGraw-Hill.

Wanninkhof, R., P. J. Mulholland, and J. W. Elwood. 1990. Gas-exchange rates for a 1st-order stream determined with deliberate and natural tracers. Water Resour. Res. 26: 1621-1630. doi:10.1029/WR026i007p01621

\section{Acknowledgments}

We thank three anonymous reviewers and Associate Editor Clare Reimers for helpful and constructive comments on the manuscript. We are grateful to the JFE Advantech engineering team in Japan who worked skillfully on the new oxygen-temperature sensor tested in this study. We also thank Rachel E. Michaels for editorial assistance on the manuscript. Finally, we thank Julie and John Baird who allowed us to work in the Hardware River on their property. This study was supported by grants from the National Science Foundation (OCE-1061364, OCE-1334848) and the University of Virginia.

Submitted 10 April 2015

Revised 13 September 2015

Accepted 22 September 2015

Associate editor: Clare Reimers 